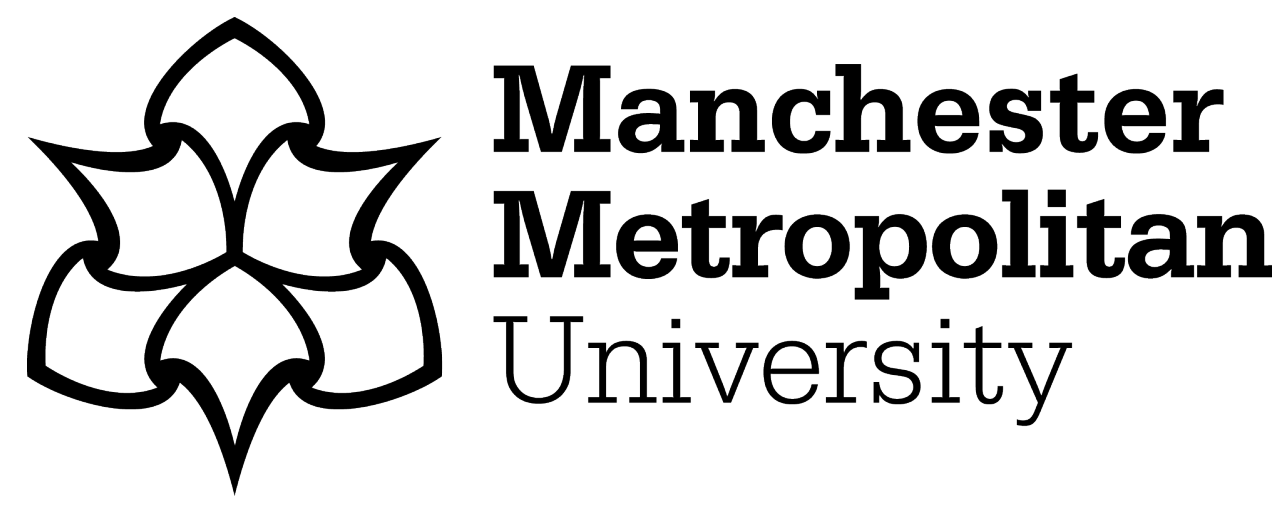

Liao, Y, Lian, Z, Yuan, H, Feng, J and Cui, H (2019) Optimization of an intrinsically safe solenoid valve and the static and dynamic characteristics. International Journal of Applied Electromagnetics and Mechanics, 61 (1). pp. 111-122. ISSN 1383-5416

Downloaded from: https://e-space.mmu.ac.uk/627072/

Version: Accepted Version

Publisher: IOS Press

DOI: https://doi.org/10.3233/JAE-190011

Please cite the published version 


\title{
Optimization of an intrinsically safe solenoid valve and the static and dynamic characteristics
}

\author{
Authors: Yaoyao Liao ${ }^{\mathrm{a}, \mathrm{b},{ }^{*}}-$ Zisheng Lian ${ }^{\mathrm{a}, \mathrm{b}} \quad$ - Hongbing Yuan ${ }^{\mathrm{a}, \mathrm{b}} \quad$ Jiling Feng $^{\mathrm{c}} \quad$-Hongwei Cui ${ }^{\mathrm{a}, \mathrm{b}}$ \\ Affiliations: \\ ${ }^{a}$ College of Mechanical Engineering, Taiyuan University of Technology, Taiyuan 030024, PR China \\ ${ }^{\mathrm{b}}$ Shanxi Key Laboratory of Fully Mechanized Coal Mining Equipment, Taiyuan 030024, PR China \\ 'School of Engineering, Manchester Metropolitan University, M1 5GD, UK
}

Address: Yingze West Avenue 79, Taiyuan 030024, PR China

Corresponding author: Yaoyao Liao, Email: lyynihao0709@163.comＴel: +86 18734901887

\begin{abstract}
The solenoid valve used on the hydraulic roof support in the coal mine is an intrinsically
safe solenoid. It requires the solenoid valve to achieve large electromagnetic force at low current. The load can not be driven if the current is too low, while a large temperature rise and energy loss would occur in the form of heat if the current is too high. In order to solve this contradictory problem, the load force of the solenoid valve was analyzed first. Then the ANSYS models of the solenoid were established to carry out the simulation jobs. The effects of the three parameters, the sleeve length, the seat length and the boss height, on the electromagnetic forces and magnetic fields were researched so as to optimize the three parameters. The static and dynamic characteristics of the optimized solenoid valve were also studied. An experimental setup was established to verify the simulation results finally. Results show that the simulation values are in good agreement with the experimental values. The peak value of starting current and holding current is small and the solenoid responses rapidly. This study proves the accuracy and reliability of the simulation models and the methods. It also provides valuable references for the design and optimization of the intrinsically safe solenoid valve.
\end{abstract}

Keywords: Solenoid; Electromagnetic force; Magnetic field; ANSYS; Hydraulic roof support 


\section{Introduction}

Solenoid valve is an important electro-mechanical conversion component which is widely used for automatic control in the aerospace equipments, marine equipments, mining equipments and other industrial machines. Generally speaking, the most important indicator of an solenoid valve is the electromagnetic force[1-4] which is affected by many factors such as the current, coil number, volume and so on[5-6]. However, there are strict restrictions on the solenoid valve used in the coal mine for the safety reasons. For example, the current is not allowed to exceed $200 \mathrm{~mA}$, and the voltage is $12 \mathrm{~V}$, so it requires large electromagnetic force at low power and is difficult to design the intrinsically safe solenoid valve.

Many scholars investigated on the force calculation of the solenoid valve in the past. Some scholars used the theoretical model to calculate the electromagnetic force and found ways to increase it, but the models were simplified a lot and it leaded to big errors[7-8]. Some others used double coils to increase the electromagnetic force[9], but this type of solenoid valve is much larger and takes up more space, so it is not suitable for the hydraulic support used in the coal mine. Some ones used the materials with good magnetic permeability to increase the electromagnetic forces[10-12], but it is hard for these materials to meet the harsh environment in the coal mine because it is wet and corrosive. Furthermore, with the modern development of computer analysis technology, many scholars use the finite element method to improve the distribution of magnetic fields in order to shorten the design process, reduce the cost and improve the design efficiency[13-16]. However, most people focused too much on the magnetic force, and they ignored the static and dynamic characteristics of the solenoid.

In this paper, the finite element method is used to optimize the key structural parameters, and the static and dynamic characteristics of the optimized solenoid are also studied. 


\section{The models}

\subsection{Structure and force analysis}

Fig.1 shows the electro-hydraulic valve used on the hydraulic support in the coal mine. The electro-hydraulic valve is consisted of two parts, one is the solenoid valve, and the other one is a hydraulic valve. The output force of the solenoid valve can make the hydraulic valve open and close. The detailed working principle is as the following: when the coil of the solenoid is energized, the armature moves to the right under the action of the electromagnetic force and pulls the lower part of the lever, then the output force of the solenoid valve is amplified through the lever. The amplified force, overcoming the resistant forces such as the spring force of the hydraulic valve, makes the moving components move to the right. Thus, the pressure port $\mathrm{P}$ is connected to port $\mathrm{A}$. In this case, the hydraulic valve begins to work. On the contrary, when the coil of the solenoid valve is de-energized, the armature of the solenoid valve and the moving components of the hydraulic valve both move to the initial left side by the respective springs. Then port $\mathrm{P}$ is disconnected to port $\mathrm{A}$. The hydraulic valve stops work.

The electromagnetic force is so important that it directly depends whether the moving components of the hydraulic valve can move reliably. The opening actions can be divided into two stages as the following.

(1) The initial stage

The moving components begin to move at this stage. The electromagnetic force must satisfy the following inequality (1).

$$
F_{\mathrm{c}}>\left(F_{\mathrm{fh}}+F_{\mathrm{sh}}\right) / a+F_{\mathrm{ss}}+F_{\mathrm{m}}
$$

where, $F_{\mathrm{c}}$ is the electromagnetic force. $F_{\mathrm{fh}}, F_{\mathrm{sh}}, F_{\mathrm{ss}}, F_{\mathrm{m}}$ represent the friction force of the hydraulic valve, 
the pre-compression force of the spring for the hydraulic valve, the pre-compression force of the spring for the solenoid valve, the friction force of the moving armature and the rod, respectively. They are $3.21 \mathrm{~N}, 28 \mathrm{~N}, 0.45 \mathrm{~N}, 0.45 \mathrm{~N} . \alpha=10$, which is the magnification factor of the lever. According to the above calculation, the initial electromagnetic force should be:

$$
F_{\mathrm{c}}>4.0 \mathrm{~N}
$$

(2) The working stage

When the moving components move to the right side at the maximum opening state, the electromagnetic force meets the following force inequality (3).

$$
F_{c}>\left(F_{s h}^{\prime}-F_{w}+F_{f h}\right) / a+F_{s s}^{\prime}+F_{m}
$$

where, $F_{\mathrm{sh}}{ }^{\prime}, F_{\mathrm{w}}, F_{\mathrm{ss}}$ ' represent the spring force of the hydraulic valve, the steady flow force and the spring force of the solenoid valve. They are $29.6 \mathrm{~N}, 10.4 \mathrm{~N}, 1.2 \mathrm{~N}$, respectively. According to the above calculation, the initial electromagnetic force should be:

$$
F_{\mathrm{c}}>3.89 \mathrm{~N}
$$

It should be noted that the pressure force is not taken into consideration in the above equations because the pressure force is balanced in the structure design of the hydraulic valve. Above all, a lever of 10 times magnification is used to increase the output force of the solenoid valve. The output force of the solenoid valve should at least be $4 \mathrm{~N}$.

\subsection{Simulation model}

The maximum opening of the hydraulic valve is $0.2 \mathrm{~mm}$, so the output displacement of the solenoid valve should be at least $2 \mathrm{~mm}$. On the basis of this, an intrinsically safe solenoid valve is designed. The two dimensional sectional view of the solenoid valve is shown in Fig.2. The three parameters, the sleeve length $l$, the seat length $m$, the boss height $n$, affect the magnetic fields and the 
electromagnetic force, so they would be optimized.

The solenoid valve is geometrically axial symmetric. In order to reduce the amount of calculation and the number of iterations, only $1 / 2$ two dimensional model is selected for calculation. Its simulation model in ANSYS is shown in Fig.3. Then different parts of the solenoid valve should be defined with different material properties. The coil and rod material should be copper which is antimagnetic and can be directly selected in ANSYS. The armature should use the material with good magnetic permeability, so the electrician pure iron is selected. The seat and the cover are selected as SA1010 steel which is a type of low carbon steel. The air gap as well as the external fields is filled with air, of which the magnetic permeability is defined as 1 . Then the model is meshed wish triangle and quadrilateral meshes. Next, the load should be applied on the model. Here, the current density, $3330000 \mathrm{~A} / \mathrm{m}^{2}$, is applied to the coil. Then the calculation begins.

\section{Experimental tests}

The purpose of the experimental tests is to measure the static and dynamic characteristics of the solenoid valve. The static characteristics can be reflected by two items, one is the displacement-force curve which indicates the load capacity of the armature at different positions, and the other one is the current-force curve which reveals the load capacity of the intrinsically safe solenoid valve at different excitation currents. The dynamic characteristics can be reflected by the transient current or the transient displacement of the solenoid valve under step voltage excitations. It represents the rapid response capability of the solenoid valve.

The principle of the experimental system is shown in Fig.4. The solenoid valve is fixed on the supporting platform, and the moving platform driven by the combination of a servo motor and a lead screw-nut mechanism moves to change the relative position between the solenoid valve and the moving 
platform. A load transducer which can be used to measure the electromagnetic force of the solenoid valve and an eddy current displacement sensor which can be used to test the air gap or the displacement of the solenoid valve, are mounted on the moving platform. A grating scale is used to feedback the position of the moving platform. A current sensor is used to test the transient current of the coil. All the moving actions and the data acquisition are controlled by the NI host computer and the Labview software. Fig. 5 shows the corresponding experimental setup. It is noted that each experimental data in this study is the average value of three tested groups.

\section{Analysis of the results}

\subsection{Effects of the key parameters}

(1) the influence of sleeve length $l$

In the simulation models, all the parameters are kept the same except the sleeve length $l$ which varies from 0 to $23 \mathrm{~mm}$. The initial electromagnetic forces at different sleeve length are obtained as Fig.6 shows. It can be seen that the electromagnetic force rises slowly when $l$ increases from 0 to 20 $\mathrm{mm}$ and falls down sharply when $l$ increases from $20 \mathrm{~mm}$ to $23 \mathrm{~mm}$. The reason can be found out through the analysis of the distribution of magnetic lines of flux at different sleeve length in Fig.7. It is clear that when $l$ increases from 0 to $20 \mathrm{~mm}$, more and more magnetic lines pass through the sleeve and the armature, so the electromagnetic force rises slowly. But when $l$ exceeds $20 \mathrm{~mm}$, the distance between the sleeve and the seat is smaller than the distance between the armature and the seat. So many magnetic lines pass through the gap between the sleeve and the seat rather than through the working air gap between the armature and the seat. Therefore, it is a matter of course that the electromagnetic force becomes sensitive to the sleeve length when $l>20 \mathrm{~mm}$ and falls down rapidly with the increase of $l$. So it can be conclude that the electromagnetic force reaches to the maximum value which is $1.7 \mathrm{~N}$ when 
$l=20 \mathrm{~mm}$.

Suitable distance between the sleeve and the seat not only affect the distribution of the magnetic lines of flux, but also brings the largest electromagnetic force.

(2) the influence of seat length $m$

There are 11 lengths selected as the simulation models in this part. The seat length $m$ ranges from $12.6 \mathrm{~mm}$ to $32.6 \mathrm{~mm}$, one type every $2 \mathrm{~mm}$. The obtained relationship between the electromagnetic force and the seat length in ANSYS is revealed in Fig.8. It is clear that the electromagnetic force increases with the seat length first and then decreases. When $m=22.6 \mathrm{~mm}$, where the working air gap is in the middle of the coil, the electromagnetic force is the highest which is $4.7 \mathrm{~N}$. Fig.9 shows the three maps of distribution of magnetic lines of flux. It can be seen that when $m$ increases from $12.6 \mathrm{~mm}$ to $32.6 \mathrm{~mm}$, the number of leakage magnetic lines of flux from the armature increases while number the leakage magnetic lines of flux from the seat decreases, and the total number of leakage magnetic lines of flux decreases first and then increases, so the total number of magnetic lines of flux passing through the working gap increases first and then decreases. When $m=22.6 \mathrm{~mm}$, the total leakage flux is the least and the magnetic flux passing through the working air gap is the most, so the electromagnetic force is the biggest.

(3) the influence of boss height $n$

14 sets of model are chosen to carry out the simulation when the boss height varies from $0.5 \mathrm{~mm}$ to $3 \mathrm{~mm}$. The initial electromagnetic forces at different boss height are obtained as Fig. 10 shows. It can be seen that the force increases uniformly with the increase of the boss height. The forces reaches the maximum value when $n=2.4 \mathrm{~mm}$. Then the force drops rapidly when the boss height keeps on increasing. The truth can be revealed through Fig.11 which the distribution of magnetic lines of flux at 
different boss height. As the boss height increases, more and more magnetic fluxes pass through the boss and the main working air gap while the number of magnetic fluxes passing through the bottom of the boss becomes less, so the output force increases reasonably. When the boss height goes on increasing, the right side corner of the boss is so close to the seat that many magnetic flux lines pass from the sharp corner to the seat, and the number of the magnetic flux lines passing through the working air gap decreases, so it is a matter of course that the output force drops rapidly. It can be concluded that the electromagnetic force can increases greatly if the boss height increases properly until the right side of the boss is close the seat.

\subsection{Static characteristics}

Fig.12 is relationship between the working air gap and the electromagnetic force under different currents. It can be seen from the figure that the simulation results agree well with the experimental results, which proves that the simulation method and the results are reliable. On the whole, the higher the current value, the larger the electromagnetic force under the same air gap. However, it does not mean that the higher the current, the better, because bigger current causes serious temperature rise and too much energy to be wasted in the form of heat during the holding stage of the solenoid valve when the hydraulic valve is working, so the lower current should be selected as long as it meets the initial force requirements. It can be seen that as the size of the air gap increases, the electromagnetic force becomes lower. Since the air gap size designed in this study is $2 \mathrm{~mm}$ which is the initial state, more attention should be paid to the situation at $2 \mathrm{~mm}$. It can be seen from the enlarged view that electromagnetic force is greater than $4 \mathrm{~N}$, which meets the force requirement at the initial stage, when the current is $100 \mathrm{~mA}$ and $110 \mathrm{~mA}$. When the current is $100 \mathrm{~mA}$, the electromagnetic force is $4.2 \mathrm{~N}$ which is a little bigger than the minimum requirement and is safe in practical applications, so $100 \mathrm{~mA}$ 
can be sected as the supplying current. The result is benefit for the circuit design of the coil.

\subsection{Dynamic characteristics}

The transient responses of current and the displacement of the solenoid valve can be used to evaluate the dynamic characteristics. Fig.13-Fig.15 are the step responses of current, opening displacement and the closing displacement when the coil is supplied with DC $12 \mathrm{~V}$ excitation voltage. It is clear that the experimental values are close to the simulation values, indicating that the simulation models and the methods are accurate and reliable. The maximum current is below $200 \mathrm{~mA}$ which is the maximum allowed value for the Intrinsically safe solenoid valve and the response of displacement is rapid. However, in general, the tested current is greater than the simulation current and the experimental displacement lags behind the simulation result, it may be caused by the friction force which is hard to be considered in the ANSYS model. The current in Fig.13 forms a peak during the rising process due to the excitation impedance of the coil. At last, the current reaches a maximum value and remains. The solenoid valve is in the holding stage during this period. The current is completely dissipated in the form of heat.

\section{Conclusions}

The ANSYS software is used in this paper to study the effects of the key parameters, such as the sleeve length, the seat length and the boss height, on the electromagnetic force, and these three parameters are optimized. On the basis of this, the static and dynamic characteristics of the optimized solenoid valve are studied through the combination of simulation and experiment. The innovations and contributions of this paper are:

(1) The electromagnetic force does not just simply increase or decrease with the sleeve length, the seat length or the boss height, but it has an optimal value due to the distribution of magnetic fields. 
Results show that the electromagnetic force reaches the highest value when the three parameter values are $20 \mathrm{~mm}, 22.5 \mathrm{~mm}, 2.4 \mathrm{~mm}$, respectively.

(2) The electromagnetic force increases with the current of the coil. When the current is $100 \mathrm{~mA}$, the electromagnetic force can meet the requirement to open the hydraulic valve in the initial state, without too much temperature rise and energy loss at the holding stage.

(3) In the test of dynamic characteristics, the transient test current is slightly higher than the simulation value, and the test displacement lags behind the simulated value. This may caused by the friction force during the tests. However, the simulation results are very close to the test values overall, indicating the accuracy of the simulation model and the methods.

The research results can provide significant references for the design and optimization of the intrinsically safe solenoid. 


\section{Acknowledgements}

The authors thank the support of Shanxi Science and Technology Department, under project numbers 201701D221139 and 201705D121016. We also thank the support of the National Natural Science Foundation of China, under project number U1610251. 


\section{References}

[1] T.Matsuda, T.Okamura, M.Hamada, etc, Degradation of the performance of an epoxy-impregnated rebco solenoid due to electromagnetic forces, Cryogenics 90(2018), 47-51. doi: 10.1016/j.cryogenics.2018.01.002.

[2] G.A.Shneerson, Minimization of electromagnetic forces on solenoid wall in external magnetic field, Technical physics letters 37(2011), 914-916. doi: 10.1134/S1063785011100129.

[3] J.H.Zhao, Y.Shi, L.Grekhow, etc, Effects of structure parameters on the static electromagnetic characteristics of high speed solenoid valves, International journal of applied electromagnetics and mechanics 55(2017),45-60. doi: 10.3233/JAE-160129.

[4] T.Yonezu, K.Watanabe, E.Suzuki, etc, Study on electromagnetic force characteristics acting on levitation/guidance coils of a superconducting maglev vehicle system, IEEE transactions on magnetics 53(2017), article number:8300605. doi: 10.1109/TMAG.2017.2697002.

[5] P.Liu, L.Y.Fang, Q.Hayat, etc, Research on key factors and their interaction effects of electromagnetic force of high-speed solenoid valve, Scientific world journal 2014, article number:5672242. doi: 10.1155/2014/567242.

[6] M.Sakashita, K.Nishi, S.Ito, etc, Postcorrection of current/voltage and electromagnetic force for efficient hysteretic magnetic field analysis, IEEE transactions on magnetics 53(2017), article number:7001104. doi: 10.1109/TMAG.2017.2660542.

[7] C.W.Kim, J.Y.Choi, Parameter analysis of tubular-magnetic couplings with halbach array magnetized permanent magnet by using analytical force calculation, Journal of magnetics 21(2016), 110-114. doi: 10.4283/JMAG.2016.21.1.110.

[8] Hovhannisyan, T.Andranik, Calculation of the tractive electromagnetic force of the long stroke 
solenoid, Izvestiya vysshikh uchebnykh zavedenii. Elektromekhanika 6(2014),28-31. doi: $10.17213 / 0136-3360-2014-6-28-31$.

[9] P.Arpaia, L.De.Vito, A.Esposito, etc, On-field monitoring of the magnetic axis misalignment in multi-coils solenoids, Journal of instrumentation 13(2018), article number:P08017. doi: 10.1088/1748-0221/13/08/P08017.

[10] C.David, B.Arumugam, A.Rajamani, etc, Modeling the collective excitations in a full Heusler Co-2 FeA10.5 Si-0.5(CFAS) spin valve magnetic nanopillar in the electromagnetic field, Journal of magnetism and magnetic materials 372(2014),59-67. doi: 10.1016/j.jmmm.2014.07.009.

[11] R.Wesche, X.Sarasola, K.Sedlak, etc, Demo central solenoid design based on the use of HTS sections at highest magnetic field, IEEE transactions on applied superconductivity 28(2018), article number:4203605. doi: 10.1109/TASC.2018.2797955.

[12] E.Moaseri, M.Karimi, B.Bazubandi, etc, Alignment of Carbon Nanotubes in Bulk Epoxy Matrix using magnetic-assisted method:solenoid magnetic field, Polymer science series A 59(2017),726-733. doi: 10.1134/S0965545X1705011X.

[13] X.Y.Guan, X.Wei, X.Y.Song, etc, FE analysis on temperature,electromagnetic force and load capacities of imperfect assembled GIB plug-in connectors, Applied computational electromagnetics society journal 33(2018),697-705.

[14] W.Cherief, Y.Avenas, S.Ferrouillat, etc, Effects of the magnetic field direction on forced convection heat transfer enhancements in ferrofluids, European physical journal-applied physics 71(2015), article number:10901. doi: 10.1051/epjap/2015150059.

[15] M.Lahdo, T.Strohla, S.Kovalev, etc, Magnetic propulsion force calculation of a 2-Dof large stroke actuator for high-precision magnetic levitation system, Applied computational electromagnetics society 
journal 32(2017),663-669.

[16] F.X.Hart, The magnetic field along the axis of a short,thick solenoid, Physics teacher 56(2018),104-106. doi: 10.1119/1.5021438. 


\section{Figure captions}

Fig. 1. The structure of the electro-hydraulic valve

Fig. 2. The two dimensional sectional view of the solenoid valve

Fig. 3. The ANSYS model of the solenoid valve

Fig. 4. Principle of the experimental system

Fig. 5. The experimental setup

Fig. 6. Electromagnetic force at different sleeve length

Fig. 7. The distribution of magnetic lines of flux at different sleeve length

Fig. 8. Electromagnetic force at different seat length

Fig. 9. The distribution of magnetic lines of flux at different seat length

Fig. 10. Electromagnetic force at different boss height

Fig. 11. The distribution of magnetic lines of flux at different boss height

Fig. 12. Electromagnetic force at different currents

Fig. 13. Transient current characteristics

Fig. 14. Transient displacement characteristics of the opening process

Fig. 15. Transient displacement characteristics of the closing process 


\section{Figures}

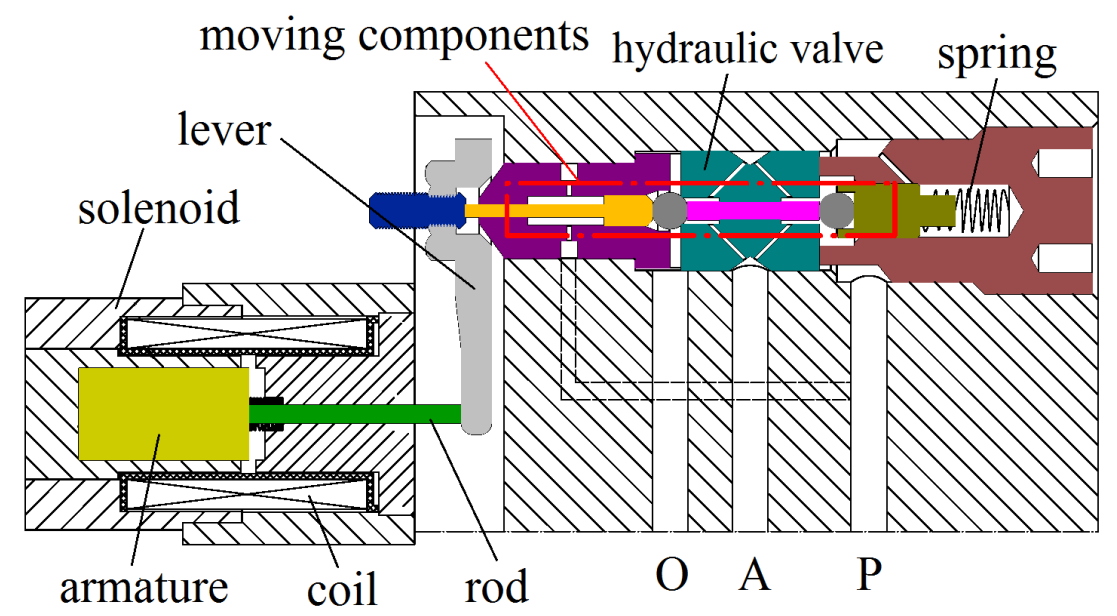

Fig. 1.The structure of the electro-hydraulic valve 


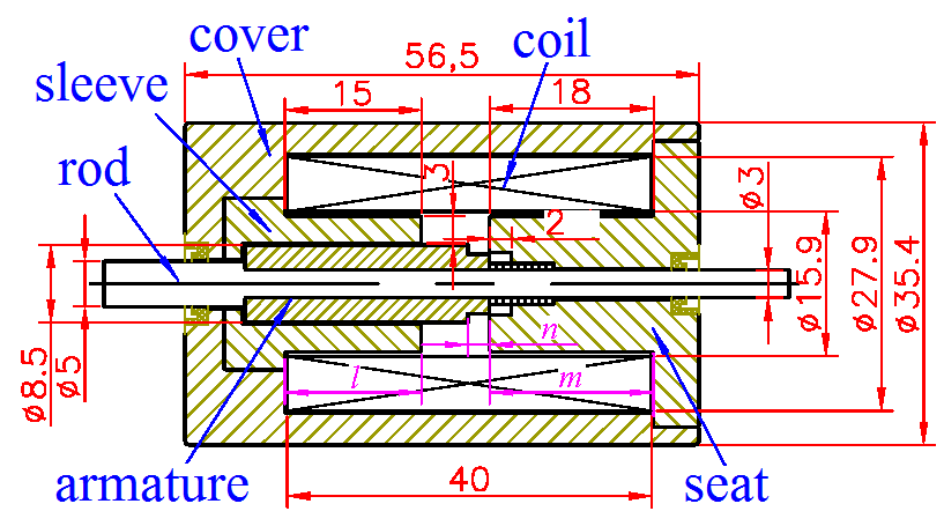

Fig. 2.The two dimensional sectional view of the solenoid valve 


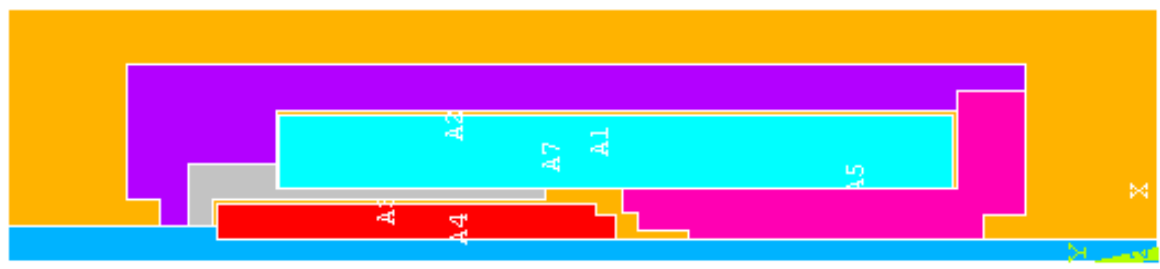

Fig. 3. The ANSYS model of the solenoid valve 


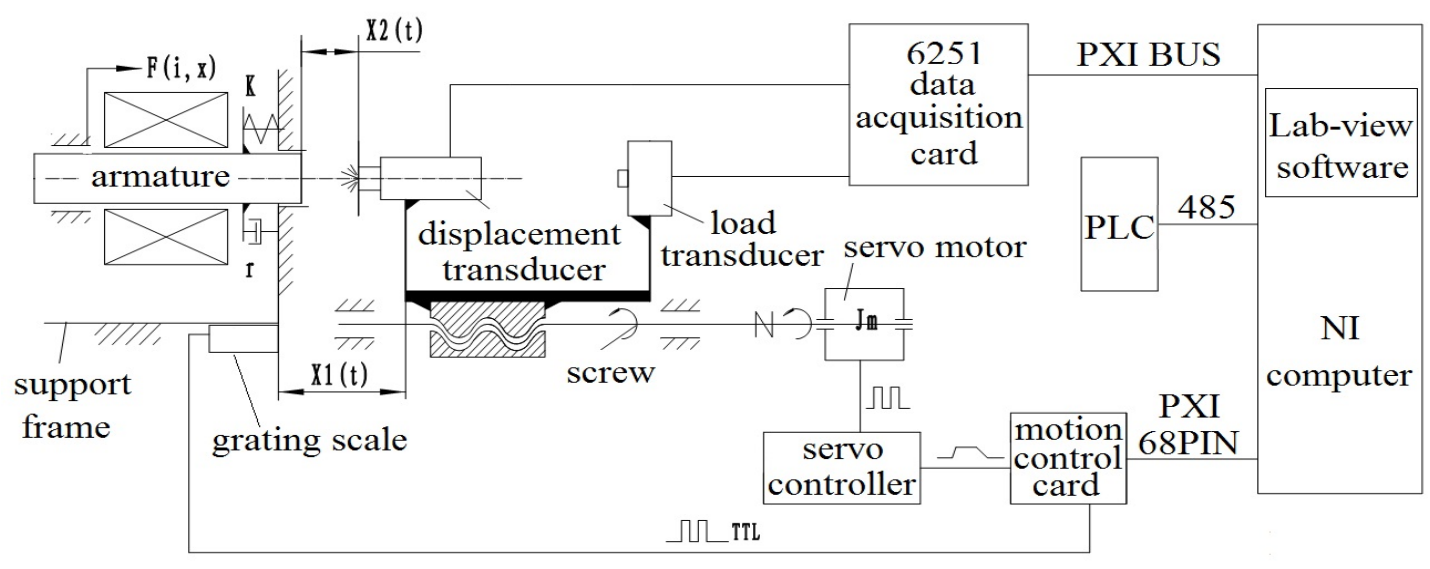

Fig. 4.Principle of the experimental system 


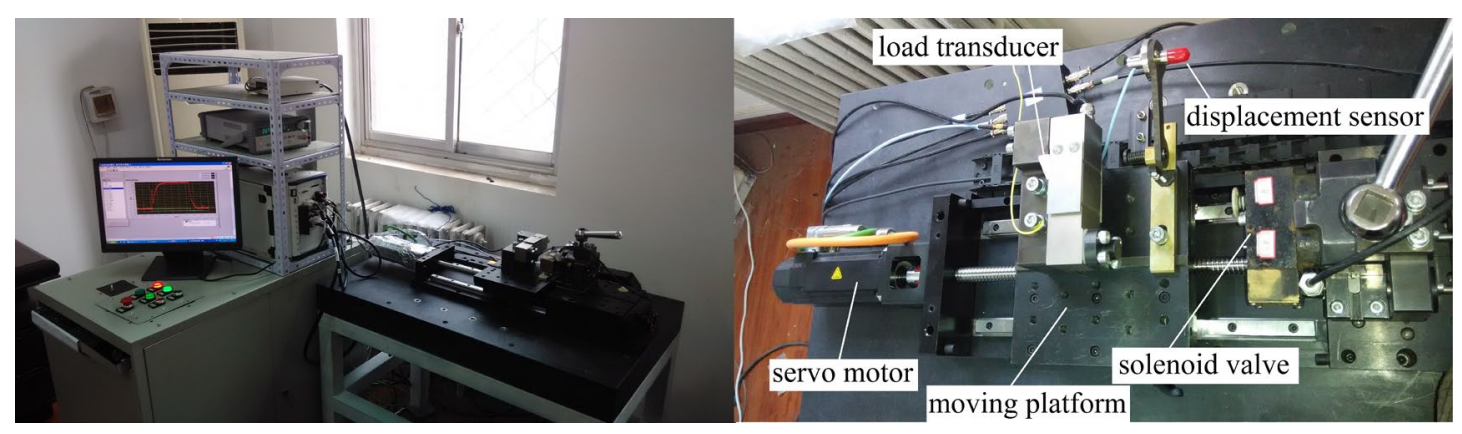

Fig. 5.The experimental setup 


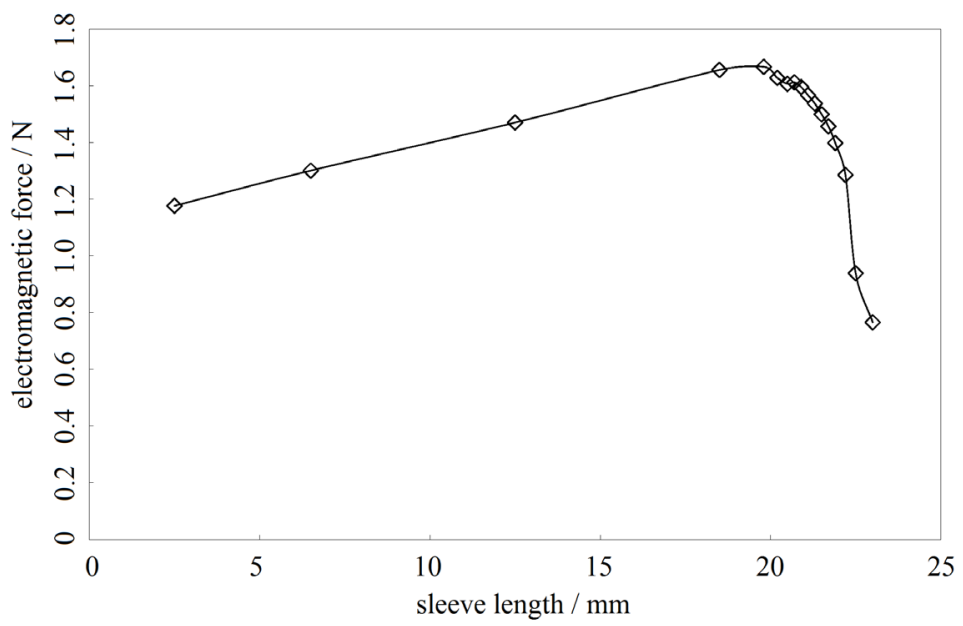

Fig. 6.Electromagnetic force at different sleeve length 


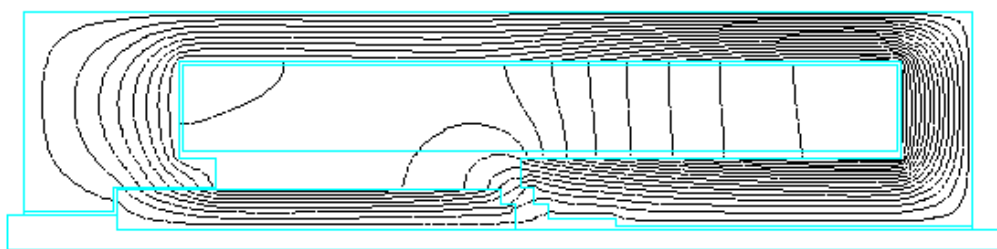

(a) $l=5 \mathrm{~mm}$

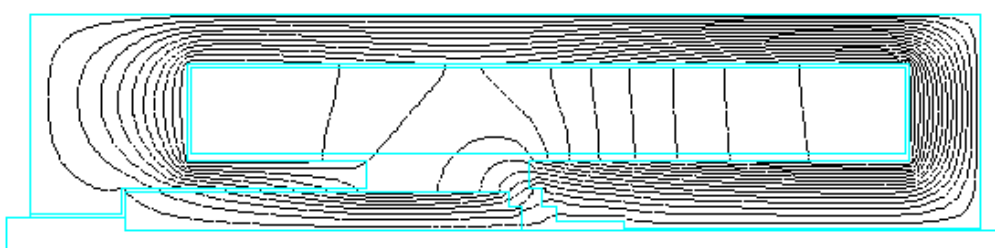

(b) $l=20 \mathrm{~mm}$

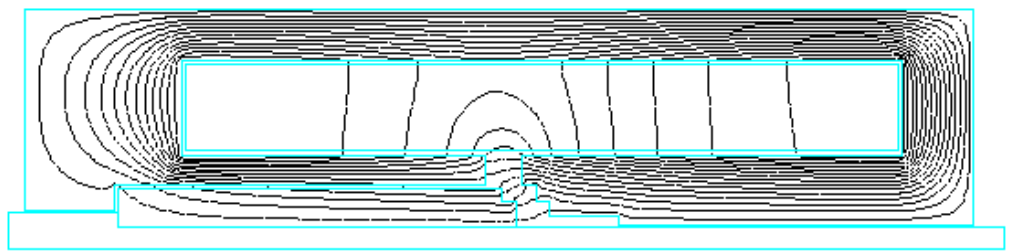

(c) $l=23 \mathrm{~mm}$

Fig. 7.The distribution of magnetic lines of flux at different sleeve length 


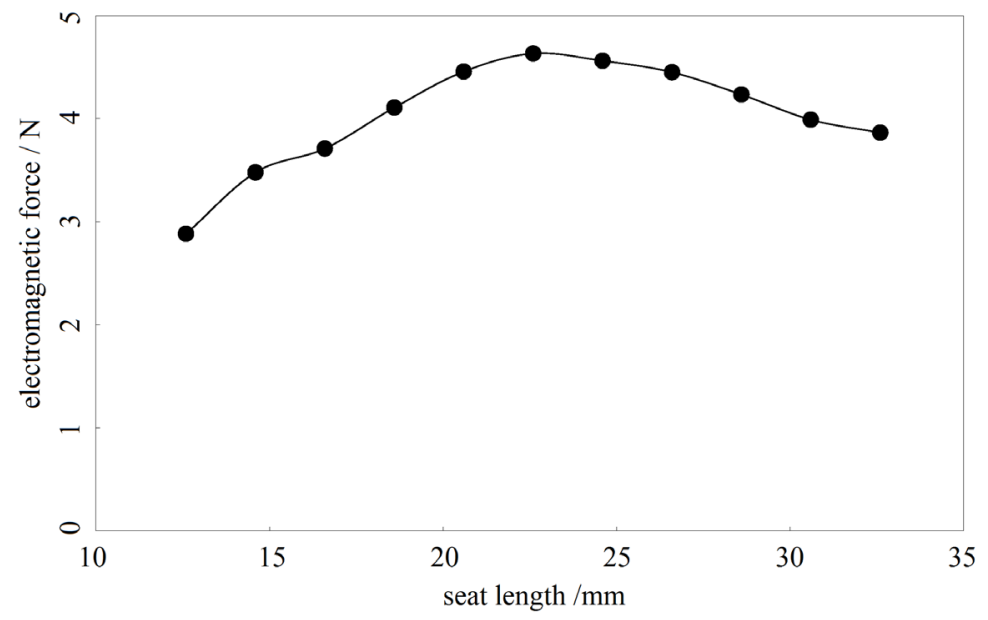

Fig. 8.Electromagnetic force at different seat length 


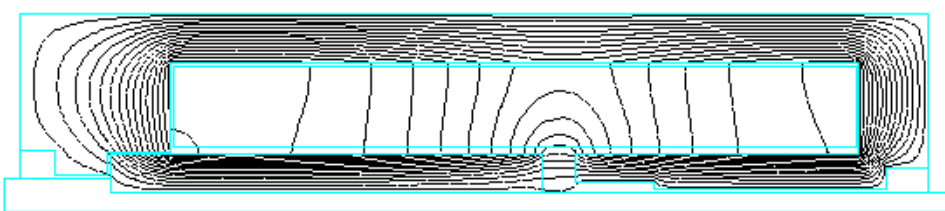

(a) $m=18.6 \mathrm{~mm}$

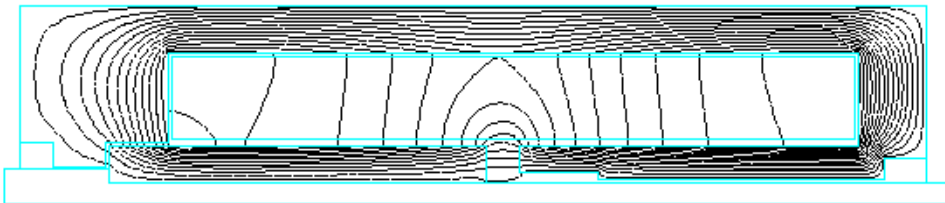

(b) $m=22.6 \mathrm{~mm}$

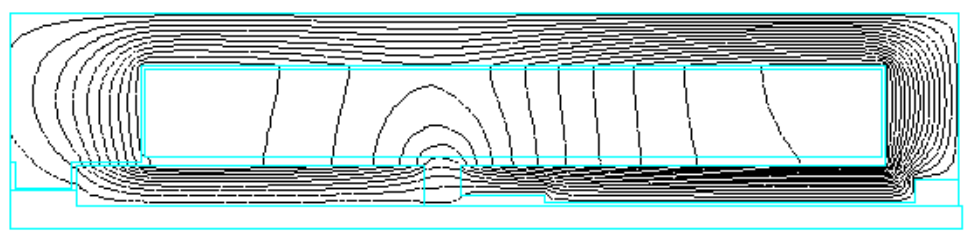

(c) $m=26.6 \mathrm{~mm}$

Fig. 9.The distribution of magnetic lines of flux at different seat length 


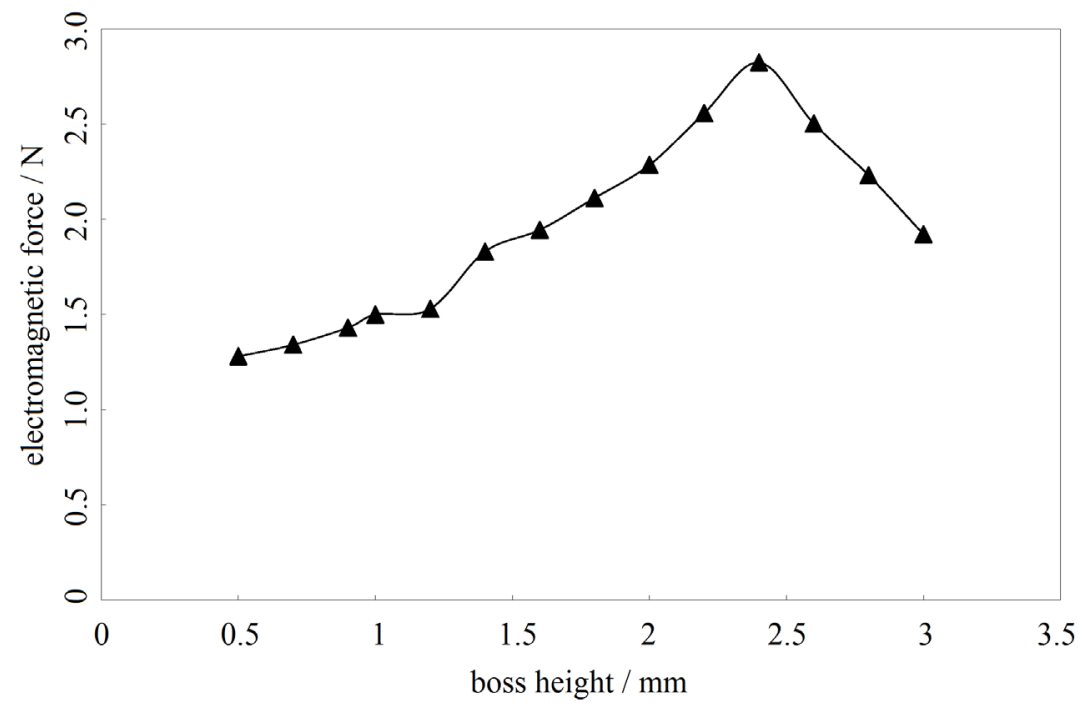

Fig. 10.Electromagnetic force at different boss height 


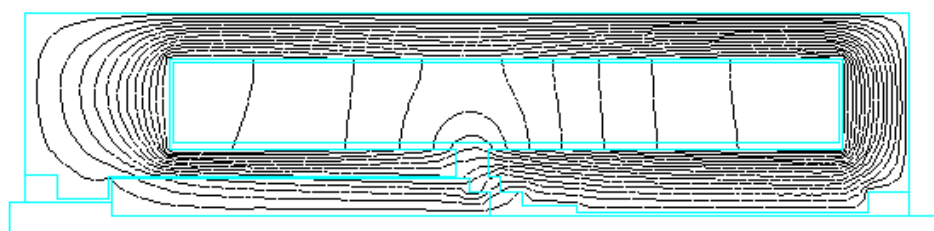

(a) $n=1.6 \mathrm{~mm}$

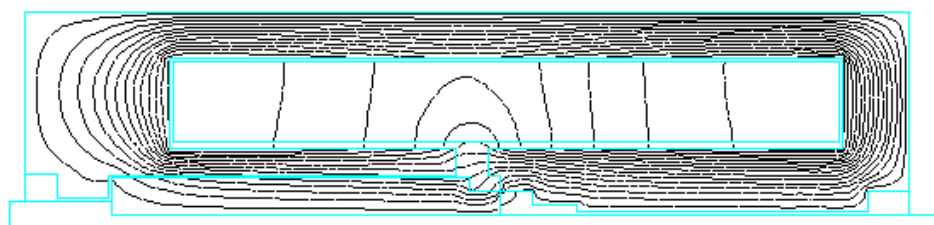

(b) $n=2.4 \mathrm{~mm}$

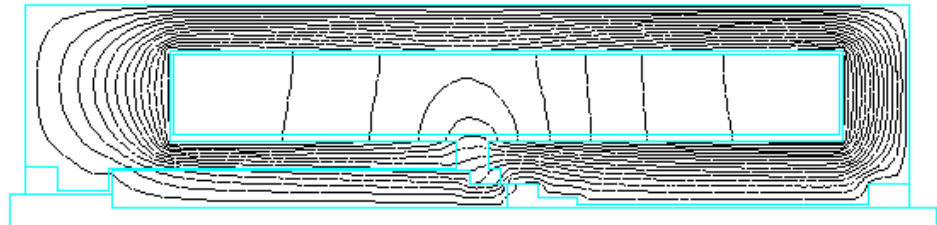

(c) $n=2.8 \mathrm{~mm}$

Fig. 11.The distribution of magnetic lines of flux at different boss height 


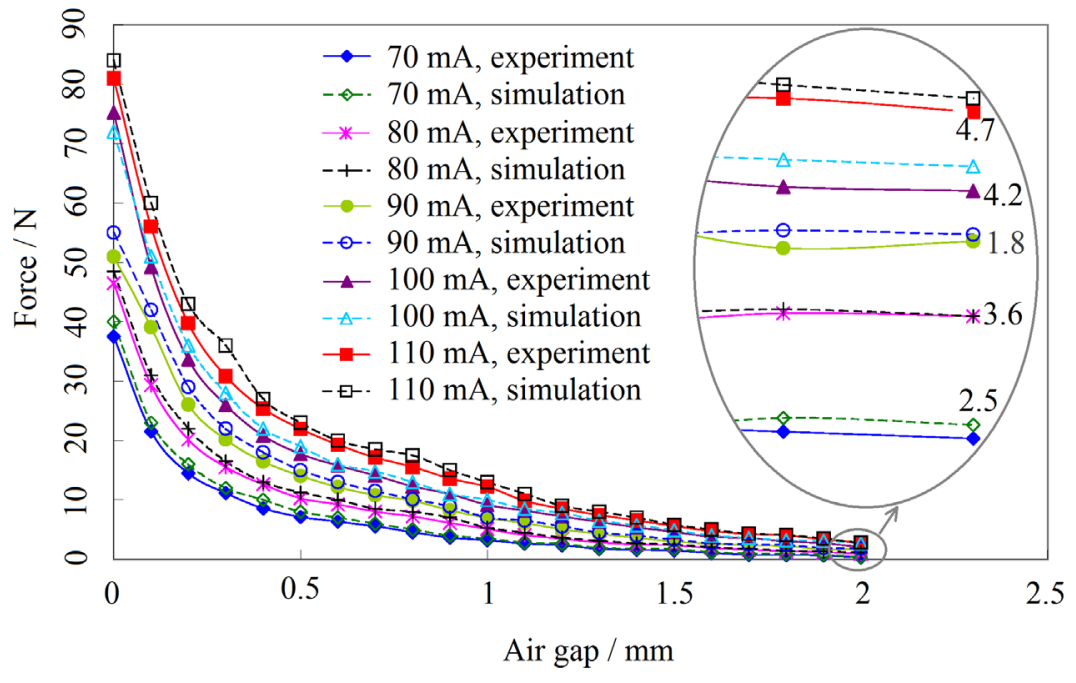

Fig. 12.Electromagnetic force at different currents 


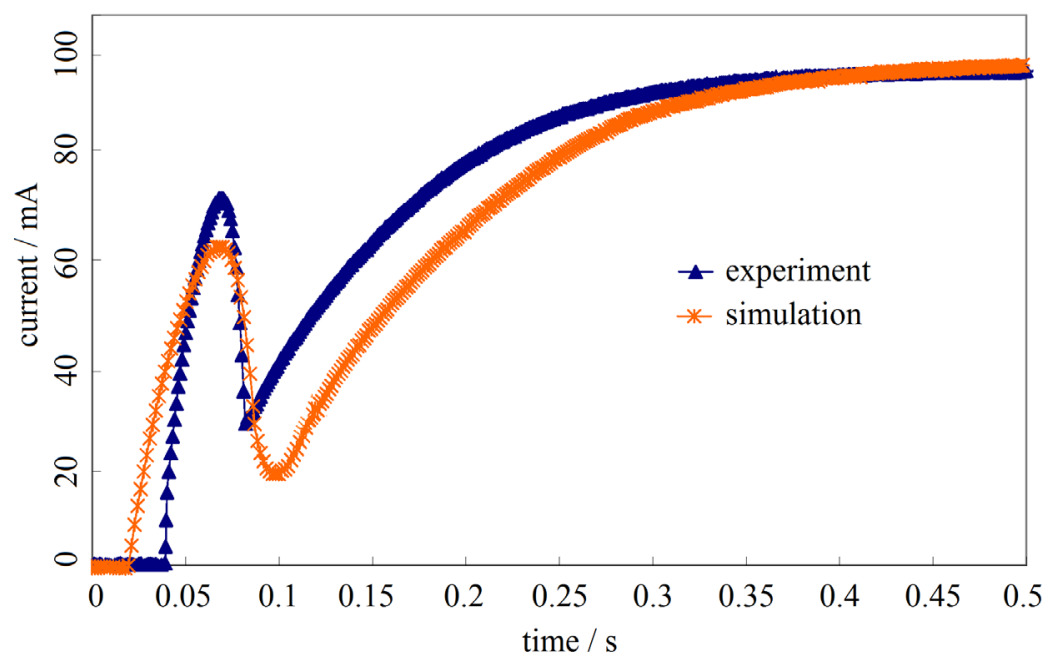

Fig. 13.Transient current characteristics 


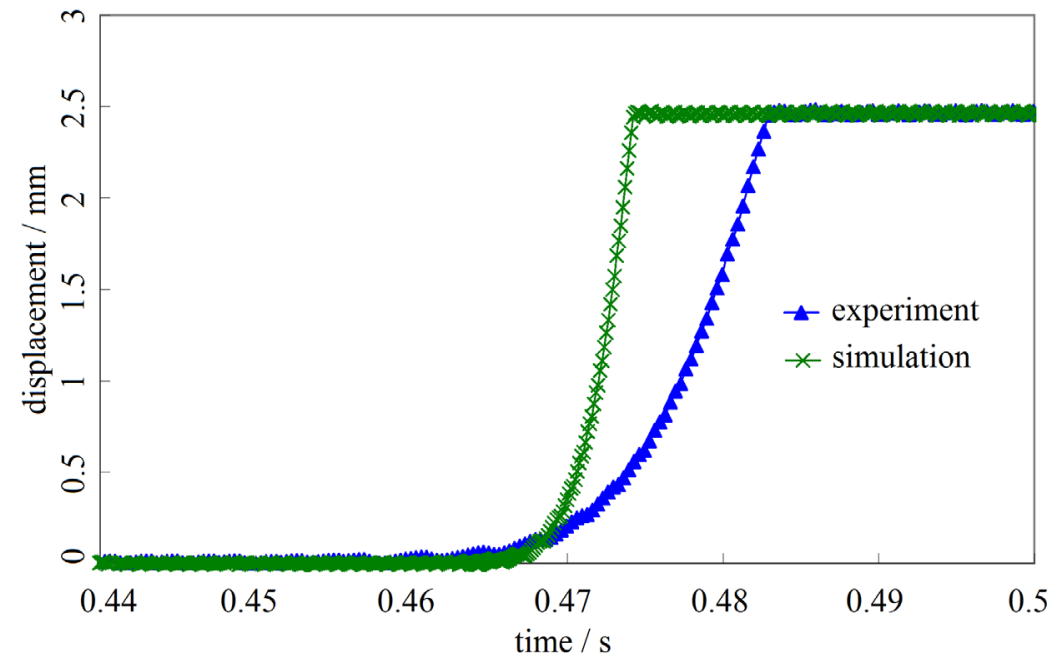

Fig. 14.Transient displacement characteristics of the opening process 


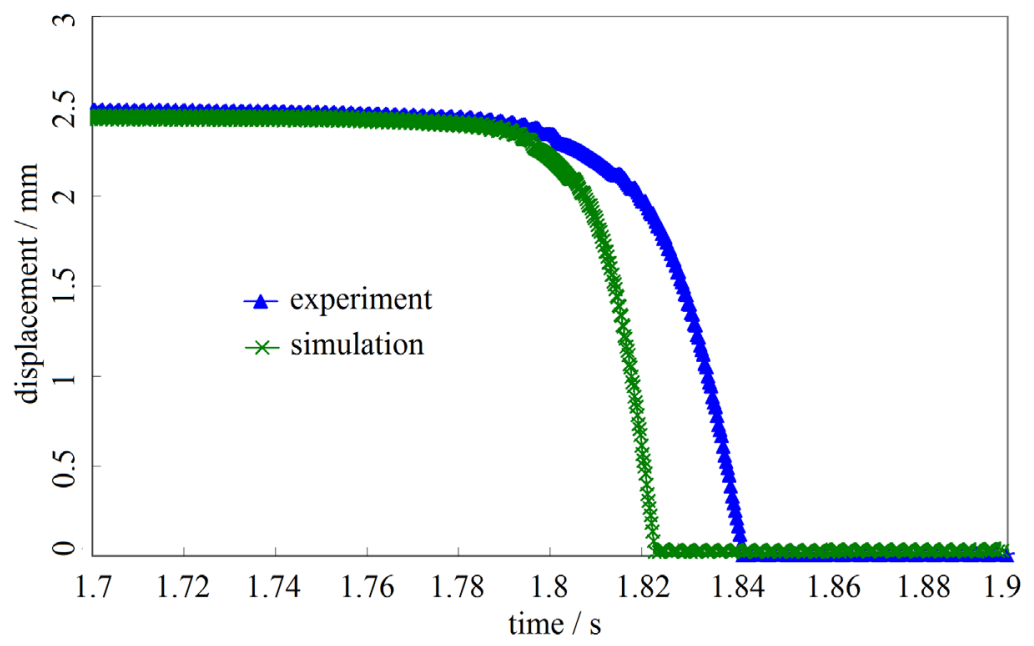

Fig. 15.Transient displacement characteristics of the closing process 